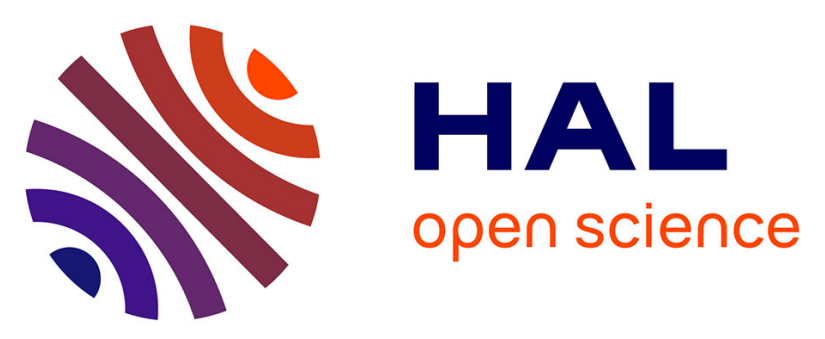

\title{
Unprecedented intramolecular cyclization in strongly dipolar extended merocyanine dyes: a route to novel dyes with improved transparency, nonlinear optical properties and thermal stability
}

Venkatakrishnan Parthasarathy, Frédéric Castet, Ravindra Pandey, Olivier Mongin, Puspendu Kumar Das, Mireille Blanchard-Desce

\section{To cite this version:}

Venkatakrishnan Parthasarathy, Frédéric Castet, Ravindra Pandey, Olivier Mongin, Puspendu Kumar Das, et al.. Unprecedented intramolecular cyclization in strongly dipolar extended merocyanine dyes: a route to novel dyes with improved transparency, nonlinear optical properties and thermal stability. Dyes and Pigments, 2016, 130, pp.70-78. 10.1016/j.dyepig.2016.03.008 . hal-01286285

\section{HAL Id: hal-01286285}

\section{https://hal-univ-rennes1.archives-ouvertes.fr/hal-01286285}

Submitted on 10 Jun 2016

HAL is a multi-disciplinary open access archive for the deposit and dissemination of scientific research documents, whether they are published or not. The documents may come from teaching and research institutions in France or abroad, or from public or private research centers.
L'archive ouverte pluridisciplinaire $\mathbf{H A L}$, est destinée au dépôt et à la diffusion de documents scientifiques de niveau recherche, publiés ou non, émanant des établissements d'enseignement et de recherche français ou étrangers, des laboratoires publics ou privés. 


\section{Accepted Manuscript}

Unprecedented intramolecular cyclization in strongly dipolar extended merocyanine dyes: a route to novel dyes with improved transparency, nonlinear optical properties and thermal stability

Venkatakrishnan Parthasarathy, Frédéric Castet, Ravindra Pandey, Olivier Mongin,

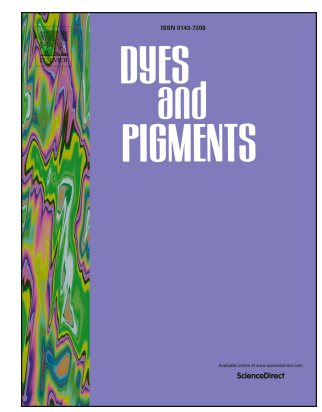
Puspendu Kumar Das, Mireille Blanchard-Desce

PII:

$$
\text { S0143-7208(16)30067-5 }
$$

DOI:

$$
\text { 10.1016/j.dyepig.2016.03.008 }
$$

Reference: DYPI 5133

To appear in: Dyes and Pigments

Received Date: 25 January 2016

Revised Date: 6 March 2016

Accepted Date: 7 March 2016

Please cite this article as: Parthasarathy V, Castet F, Pandey R, Mongin O, Das PK, Blanchard-Desce $\mathrm{M}$, Unprecedented intramolecular cyclization in strongly dipolar extended merocyanine dyes: a route to novel dyes with improved transparency, nonlinear optical properties and thermal stability, Dyes and Pigments (2016), doi: 10.1016/j.dyepig.2016.03.008.

This is a PDF file of an unedited manuscript that has been accepted for publication. As a service to our customers we are providing this early version of the manuscript. The manuscript will undergo copyediting, typesetting, and review of the resulting proof before it is published in its final form. Please note that during the production process errors may be discovered which could affect the content, and all legal disclaimers that apply to the journal pertain. 


\title{
Unprecedented intramolecular cyclization in strongly dipolar extended merocyanine dyes: a route to novel dyes with improved transparency, nonlinear optical properties and thermal stability
}

Venkatakrishnan Parthasarathy*, ${ }^{a, b}$ Frédéric Castet, ${ }^{c}$ Ravindra Pandey, ${ }^{d \dagger}$ Olivier Mongin ${ }^{b, e}$ Puspendu Kumar Das*, ${ }^{d}$ Mireille Blanchard-Desce* ${ }^{b, c}$

${ }^{a}$ Department of Chemistry, Indian Institute of Technology Madras, Chennai - 600 036, India. E-mail: pvenkat@iitm.ac.in

${ }^{b}$ Chimie et Photonique Moléculaire (CNRS, UMR 6510), Université de Rennes 1,35042 Rennes, France.

${ }^{d}$ Department of Inorganic and Physical Chemistry, Indian Institute of Science, Bangalore, 560012, India.

E-mail:pkdas@ipc.iisc.ernet.in

${ }^{c}$ Univ. Bordeaux, Institut des Sciences Moléculaires (UMR 5255 CNRS), 33405 Talence, France. E-mail: mireille.blanchard-desce@u-bordeaux.fr

${ }^{e}$ Institut des Sciences Chimiques de Rennes (CNRS, UMR 6226), Université de Rennes 1, Campus Scientifique de Beaulieu, Bât 10A, F-35042 Rennes Cedex, France.

$\dagger$ Current Address: Department of Chemistry, University of Texas at Austin, Austin TX, USA.

\begin{abstract}
Novel magenta dyes were obtained via an unprecedented base-promoted intramolecular cyclization of strongly dipolar elongated merocyanine dyes bearing a phthalimide substituted tricyanopropylidene terminal segment. These shorter diarylpolyene derivatives retain a dipolar character and show a typical intramolecular charge transfer (ICT) transition. The cyclization noticeably modifies the electronic structure inducing both onset of bond length alternation and reduction of dipole moment as well as a marked hypsochromic and hypochromic shift of the ICT absorption band compared to their merocyanine precursors. Yet the new dyes show improved quadratic hyperpolarizability and thermal stability as compared to the merocyanine dyes having the same number of conjugated double bonds in the polyenic linker. As such these derivatives hold promise as new class of dyes for NLO materials and SHG probes.
\end{abstract}

Keywords: Merocyanine dyes; Hyperpolarizability; Hyper-Rayleigh scattering; Nonlinear Optics; Intramolecular Charge Transfer 


\section{Introduction}

Push-pull chromophores have gained tremendous interest in recent decades due to their many applications in various fields including nonlinear optics (NLO), NLO bioimaging, biochemical sensing, solar cells, etc. ${ }^{1}$ Push-pull systems are generally composed of an electron-releasing group (or donor D) connected to an electron-withdrawing group (or acceptor A) via a $\pi$-conjugated linker. Among them push-pull polyenes have attracted a lot of attention due to their large electronic polarizability. A number of reports on different series of push-pull polyenes have shown that the structure of the chromophore, i.e., length of the $\pi$ conjugated chain, and nature of the D and A groups play a vital role in achieving huge optical nonlinearities (i.e., quadratic and cubic hyperpolarizabilities). ${ }^{2}$ From a synthetic point of view, in many occurrences, D- $\pi$-A based polyenic chromophores were prepared starting from the donor end followed by stepwise vinylic elongation. ${ }^{2,3}$ Elongation of the polyenic structures with terminal carbonyl functionalities was usually achieved by a Wittig oxypropenylation method $^{2 b, 4}$ or via an iminium salt (activated equivalent of aldehyde) formation. ${ }^{5}$ Finally, the end carbonyl functionalities were subjected to Knoevenagel condensation with the acceptors bearing an active methylene group or Wittig/Horner-Wadsworth-Emmons reactions with corresponding electron deficient phosphonium salts/phosphonates to achieve variety of D-A polyenic chromophores. ${ }^{2,3}$ These D- $\pi$-A molecules exhibit an intense absorption band in the visible region due to an intramolecular charge transfer (ICT) phenomenon.

In terms of acceptor group, the popularity of polycyano acceptors is well documented in the literature. ${ }^{6}$ Among them, 2-amino-1,1,3-tricyano-1-propene has caught our attention as it has been explored not only in the preparation of several dyes for application in NLO but also as a crucial building block for heterocyclic synthesis. ${ }^{7}$ In continuation to our efforts on push-pull chromophores for NLO, we recently reported the synthesis of a new set of chromophores incorporating $\mathrm{N}, \mathrm{N}$-dihexylamino-substituted thiophene as strong donor and 
phthalimide substituted tricyanopropylidene as strong acceptor while varying the $\pi$ conjugation length $(\mathrm{n})$ from $0 \rightarrow 3$ (Chart 1). For this, we followed a synthetic strategy as sketched in Scheme 1. The synthetic protocols as well as the linear and nonlinear optical properties and large dipole moments of derivatives $\mathbf{2}$ have been described in detail in our recent publication. ${ }^{8}$ Although the optical properties of such various yellow/orange or magenta dyes derived from the condensation reactions of malononitrile dimer have been measured, ${ }^{2,3}$ the fate of such in reaction media in relation to the extension of conjugation has been scarcely registered. In this report, we present an unprecedented observation that we came across during the final step of base-mediated dehydrative cyclocondensation of the $\pi$-extended amines $\mathbf{3}$ (when $\mathrm{n}>1$ ) with phthalic anhydride (Scheme 1). Interestingly, besides formation of the desired product $\mathbf{2}$, we noted a product $\mathbf{1}$ that is shorter in conjugation length (n-1) formed as a result of consecutive intramolecular cyclization (Chart 1). The resultant novel cyclized products 1, viz., phenylthienylethene derivatives, obtained along with $\mathbf{2}$ during the final step via an intramolecular cyclization are thoroughly characterized and the mechanism for the intramolecular cyclization reaction has been investigated. Herein, we focus our attention mainly on the linear and nonlinear optical as well as on the thermal properties of these newly derived products $\mathbf{1}$ and on their comparison with the analogous linear $\pi$-extended molecules 2 . The experimental studies are further supported by theoretical calculations to identify the alteration of electronic structure induced by cyclization and responsible for the modification in optical properties.

\section{Results and discussion}

\subsection{Synthesis}

The general synthetic approach for the preparation of extended push-pull chromophores is described below (Scheme 1). As shown in Scheme 1, the push-pull polyenals upon 
Knoevenagel condensation with malononitrile dimer (2-amino-1,1,3-tricyanopropene) yielded the required amino compounds $\mathbf{3}$ which upon further condensation with phthalic anhydride in the presence of triethylamine afforded the corresponding polyenic push-pull chromophores 2. ${ }^{8}$ The resultant polyenic push-pull chromophores (both amines $\mathbf{3}$ and imides 2) were strongly colored. The synthesis of the imides $\mathbf{2}$ has been published earlier ${ }^{8}$ and will thus not be discussed here in detail. Imides $\mathbf{2}$ were shown to exhibit an intriguing typical cyanine-like behavior and specific features associated with non-alternated conjugated $\pi$-system, i.e., narrow absorption band that steadily shifts from the visible to the NIR region upon increasing length (vinylenic shift of about $110 \mathrm{~nm}$ ). This cyanine-like behavior implies a significant and steady $(\rho=0.5)$ intramolecular charge transfer from the electron-donating end moiety to the electron-withdrawing opposite end in the ground state, resulting in steadily increasing dipole moment values with increasing polyenic chain length. As a result compounds $\mathbf{2 c}$ and $\mathbf{2 d}$ exhibit unusually large dipole moments (i.e. over 20D) while showing exponentially increasing quadratic polarizability $(\beta)$, thus breaking the well-known Bond Length Alternation (BLA)- $\beta$ paradigm. We propose that these unusually large dipole moment values may facilitate intramolecular cyclization in solution (see below).

Indeed during the synthesis of $\mathbf{2 c , d}$ from amines $\mathbf{3 c}, \mathbf{d}$, we observed the formation of side products 1c,d, respectively, in reasonable amounts; under the same reaction conditions, $\mathbf{3 c}$ afforded the by-product 1c in $16 \%$ yield while 3d yielded $1 \mathbf{d}$ in $32 \%$. The isolated byproducts 1c,d were soluble in common organic solvents, such as, toluene, chloroform, dichloromethane, tetrahydrofuran, ethyl acetate, etc. and they were different in color when compared to their polyenic counterparts 2 and 3. All these compounds were thoroughly characterized and identified by ${ }^{1} \mathrm{H}$ and ${ }^{13} \mathrm{C}$ NMR spectroscopy, mass spectrometry and elemental analysis. 


\section{ACCEPTED MANUSCRIPT}

\section{2. ${ }^{1} \mathrm{H}$ NMR and theoretical studies: identification of the structure of compounds 1c-d}

As mentioned earlier, the reaction from $\mathbf{3}$ to $\mathbf{2}$ afforded the side product $\mathbf{1}$ for compounds with $\mathrm{n}>1$ (Scheme 1$)$, which was isolated carefully and analyzed by ${ }^{1} \mathrm{H}$ NMR spectroscopy. ${ }^{1} \mathrm{H}$ NMR spectrum of $\mathbf{1 - 3}$ in deuterated chloroform revealed all-trans geometry for the protons at the poly[n]enic backbone. The polyenic protons were assigned based on ${ }^{1} \mathrm{H}-$ ${ }^{1} \mathrm{H}$ COSY experiments. Notably, other than the two doublets $(J=4.0 \mathrm{~Hz})$ for the thiophene protons, ${ }^{1} \mathrm{H}$ NMR spectrum of the side product $1 \mathrm{c}$ in chloroform- $d$ revealed two doublets centered at 7.73 and $7.77 \mathrm{ppm}$ with a characteristic ortho coupling value of $J=8.5 \mathrm{~Hz}$, each integrating for one proton, respectively. In addition, ${ }^{1} \mathrm{H}$ NMR spectrum of $\mathbf{1 c}$ revealed transolefinic protons at 6.61 and $7.47 \mathrm{ppm}$ with a characteristic $J$ value of $15.5 \mathrm{~Hz}$ (typical coupling of trans-olefinic protons across a purely $\mathrm{C}=\mathrm{C}$ double bond, $J=16.0 \mathrm{~Hz}$ ). The observation of two trans-olefinic protons $(\mathbf{1 c})$, in contrast to the expected five protons $(\mathrm{n}=2)$ as in $\mathbf{2 c}$, instructed a simple diarylethylene like structure (1c) with a reduction in the total number of double bonds $(\mathrm{m}=\mathrm{n}-1)$. Similarly, ${ }^{1} \mathrm{H}$ NMR spectrum for the product $\mathbf{1 d}$ obtained from 3d revealed two doublets at 7.77 and $7.80 \mathrm{ppm}$ integrating for one proton each, respectively, with a characteristic ortho coupling value of $J=8.4 \mathrm{~Hz}$. Moreover, it showed two doublets of doublets centered at 6.39 and $7.23 \mathrm{ppm}(J=11.0 \mathrm{~Hz}$ and $J=14.8 \mathrm{~Hz})$, and two doublets centered at 6.74 and $6.91 \mathrm{ppm}(J=14.8 \mathrm{~Hz})$ with each integrating to one proton, respectively. The reduction in the coupling value, i.e., $J=14.8 \mathrm{~Hz}$ from the typical transcoupling value of $16.0 \mathrm{~Hz}$ while the coupling value between vicinal protons borne by the single $\mathrm{C}-\mathrm{C}$ bond in between the two consecutive $\mathrm{C}=\mathrm{C}$ bonds is increased to $J=11.0 \mathrm{~Hz}$ (compared to $10 \mathrm{~Hz}$ for vicinal protons in antiparallel configuration linked via a purely single $\mathrm{C}-\mathrm{C}$ bond) indicates that the double bonds are indeed in conjugation. The double bond acquires some single bond character while the single bond acquires some double bond character, evidencing reduced BLA as compared to alternation of pure double and single 
bonds. Moreover, in the case of polyenic compounds the average $\Delta J$ value, as defined by the difference in coupling constants between vicinal vinylic protons along the polyenic conjugated backbone, gives an indication of the BLA in polyenic compounds. $\Delta J$ amounts to $\sim 6 \mathrm{~Hz}$ for fully alternated polyenic systems (maximum negative BLA) and $\Delta J=0 \mathrm{~Hz}$ (vanishing BLA) for non-alternated polyenic systems (typical cyanine-like behavior). ${ }^{2 b}$ Hence the intermediary value experimentally derived from the ${ }^{1} \mathrm{H}-\mathrm{NMR}$ spectrum of product $\mathbf{1 d}(\Delta J$ $=3.8 \mathrm{~Hz}$ ) indicate an intermediary BLA, close the reported optimal value for maximum quadratic hyperpolarizability $\beta .^{2}$ The fact that there are four olefinic protons in the conjugated polyenic backbone, in case of $\mathbf{1 d}$, indicates that there is reduction in the number of double bonds in the product $\mathbf{1 d}(\mathrm{m}=\mathrm{n}-1=2)$, in contrast to $\mathbf{2 d}(\mathrm{n}=3)$. Thus, ${ }^{1} \mathrm{H}$ NMR spectroscopic studies suggest a reduction of conjugation length in the side products $1 \mathbf{c}(\mathrm{m}=1)$ and $\mathbf{1 d}(\mathrm{m}=$ 2) when compared to $\mathbf{2 c}(n=2)$ and $\mathbf{2 d}(n=3)$, respectively. Moreover, as detailed above, the polyenic linker in 1d evidences intermediate BLA $(\Delta J=3.8 \mathrm{~Hz}$ instead of typically $6 \mathrm{~Hz}$ for alternated purely double and single carbon-carbon bonds), whereas compound $2 \mathbf{d}$ did not show any BLA. ${ }^{8}$

Molecular structures were further characterized using density functional theory (DFT) with the B3LYP exchange-correlation (XC) functional and the 6-311G(d) basis set. Table 1 gathers the relative Gibbs free enthalpies of the four rotamers with an all-trans configuration for the protons of the poly[n]enic backbone, as well as the geometrical parameters that characterize their degree of $\pi$-conjugation, namely the torsion angles between the conjugated bridge and the terminal donor and acceptor groups (Scheme 2), and the BLA along the conjugated linker. For a $\mathrm{C}_{1} \ldots \mathrm{C}_{2} \ldots \mathrm{C}_{3}$ sequence, $B L A_{1,3}=d_{2,3}-d_{1,2}$. For a longer conjugated chain containing $N$ carbon atoms, the BLA is defined as:

$$
B L A_{1 \ldots N}=\left(B L A_{1,3}+B L A_{2,4}+\cdots+B L A_{N-2, N}\right) /(N-2)
$$


$B L A_{1 \ldots N}=1 /(N-2) \sum_{i=1}^{N-2}\left\{\left(d_{i+1, i+2}-d_{i, i+1}\right) \times(-1)^{i+1}\right\}$

Note that within this convention, the BLA is negative along the conjugated linkers considered in the polyenic chromophores $\mathbf{1}$ and $\mathbf{2}$ (drawn in red in Chart 2).

For compounds $\mathbf{1 c}$ and $\mathbf{1 d}$, the rotamers with $\theta_{1} \sim 180^{\circ}$ and $\theta_{2} \sim 180^{\circ}$ are the most stable, and, given the energy differences, the only ones existing with a non-negligible population at room temperature. Therefore, only the latter will be considered in the following. The BLA value calculated for 1d is slightly smaller (in absolute value) than that of 1c, due to the extension of the conjugated pathway. Moreover, in agreement with evidences provided by ${ }^{1} \mathrm{H}$ NMR measurements, the linear poly[n]enes 2c-d exhibit a much smaller BLA than their cyclized counterparts $\mathbf{1 c}$ and $\mathbf{1 d}$.

\subsection{Mass spectrometric studies}

Compound 1c on examination for its mass (ESI-MS) surprisingly revealed the molecular ion peak at $m / z 565(\mathrm{M}+\mathrm{H})^{+}$. This accounts for a mass difference of $27(\mathrm{M}-27)$ when compared to the product compound 2c (molecular mass: 591) highlighting the possible elimination of $\mathrm{HCN}$ from 2c. In a similar fashion, compound 1d displayed the molecular ion peak at $m / z 590\left(\mathbf{M}^{+}\right)$, once again accounting for the loss of $\mathrm{HCN}(\mathbf{M}-27)$ from $\mathbf{2 d}$ (molecular mass: 617). Both the above observation finally attests the elimination of HCN from the direct condensation products $\mathbf{2 c , d}$ during the course of the reaction. The HRMS confirmed the exact mass of both the products $1 \mathbf{c}$ and $\mathbf{1 d}$. We note that the elimination of HCN from the tricyanopropylidene unit during the synthesis of heterocyclic compounds has been reported in the literature. ${ }^{9}$ The mass spectrometric analyses convey a possible elimination of $\mathrm{HCN}$ from the direct condensation products $\mathbf{2}$, to form $\mathbf{1}$. 


\subsection{Probing the reaction and mechanistic rationale}

Having identified the elimination of $\mathrm{HCN}$ from the direct condensation products $2 \mathrm{c}$ and $\mathbf{2 d}$, we questioned the reason for the formation of isolated side products $\mathbf{1 c}$ and $\mathbf{1 d}$ under base-mediated reaction conditions. As discussed earlier, the compound $\mathbf{3 c} / \mathbf{3 d}$ (1 equiv.) upon reaction with phthalic anhydride (3 equiv.) in presence of triethylamine (3 equiv.) yields $\mathbf{1 c} / \mathbf{1 d}$, besides the direct condensation products $\mathbf{2 c / 2 d}$, respectively. To further probe the formation of $\mathbf{1 c / 1 d}$ from 3c/3d, comparative experiments (paths A, B and C) were carried out. A representative case for $\mathbf{3 d}$ is shown below (Figure 1). All the paths A, B and C considered were thermal. While path A in figure 1 highlights the formation of $\mathbf{1 d}$ via $\mathbf{2 d}$, the other two paths $B$ and $C$ suggest the formation of $\mathbf{1 d}$ via $\mathbf{4 d}$ as an intermediate.

To test path A, the dichloromethane solution of $\mathbf{3 d}$ was treated with phthalic anhydride in presence of triethylamine at $50{ }^{\circ} \mathrm{C}(5 \mathrm{~h})$, which provided both the direct condensation product $\mathbf{2 d}(50 \%)$ and the side product $\mathbf{1 d}(32 \%)$ with complete consumption of $\mathbf{3 d}$. But when the same reaction was continued for longer duration (24h), we observed complete conversion of $\mathbf{3 d}$ to $\mathbf{1 d}$ with a concomitant disappearance of $\mathbf{2 d}$ in the reaction mixture. It seems that longer reaction times $(>5 \mathrm{~h})$ at $50{ }^{\circ} \mathrm{C}$ would result in greater proportion of these side products; at shorter reaction times $(<2 \mathrm{~h})$, the formation of the side product could not be avoided. This gave us a clue that the transformation of $\mathbf{3 d}$ to $\mathbf{1 d}$ occurs via the formation of $\mathbf{2 d}$ in the reaction medium. In order to test this hypothesis, the following conditions were tested. Firstly, the compound $\mathbf{2 d}$ was treated with triethylamine in dichloromethane under reflux conditions, for a period of $12 \mathrm{~h}$. The formation of $\mathbf{1 d}$ was observed quantitatively in the above case indicating that the formation of $\mathbf{1 d}$ proceeds via $\mathbf{2 d}$. Secondly, to understand the role of the base, we performed a blank reaction (in the absence of base) with $\mathbf{2 d}$ in only dichloromethane. Even after refluxing the dichloromethane solution of $\mathbf{2 d}$ for a period of 24 h, we did not observe the formation of $\mathbf{1 d}$ (as monitored by thin-layer chromatography (TLC) 
and ${ }^{1} \mathrm{H}$ NMR spectroscopy). The above reaction ascertained the importance of the base in the formation of the side product.

Following this observation, we went on to investigate the alternative pathway that may afford 1b, i.e., path $\mathrm{C}$ via path B. Initially, to test the possibility of pathway B, the compound 3d was treated with triethylamine in the absence of phthalic anhydride. After refluxing the reaction contents for 2 days, the dye $\mathbf{3 d}$ did not yield the compound $\mathbf{1 d}$. The absence of formation of $\mathbf{1 e}$ rules out path $\mathrm{C}$. The above experiments clearly point out the formation of $\mathbf{2 d}$ initially, followed by a consecutive base-induced reaction to yield 1c, i.e., 1c has formed via 2d. This result, in combination with mass spectrometric analysis, suggests a base-induced elimination of $\mathrm{HCN}$ from $\mathbf{2 d}$ leading to 1c. In other words, path A is preferred over paths B and $\mathrm{C}$. The reason for this difference in reactivity between $\mathbf{3 d}$ and $\mathbf{2 d}$ could be very readily discerned from the differences in their ground-state intramolecular charge transfer (i.e. polarization) and consequent dipole moment nature.

As commonly reported in the literature, the electronic structures of strong push-pull dyes can be viewed as a linear combination between neutral $(\mathbf{N})$ and the zwitterionic limiting resonance forms $(\mathbf{Z I})$ (eq.1). ${ }^{2 \mathrm{~b}, \mathrm{c}, 10}$ When the above two forms have the same contribution then it is said that the dye is in the cyanine limit (leading to vanishing BLA in the polyenic chain) and the amount of ICT in the ground state is 0.5 .

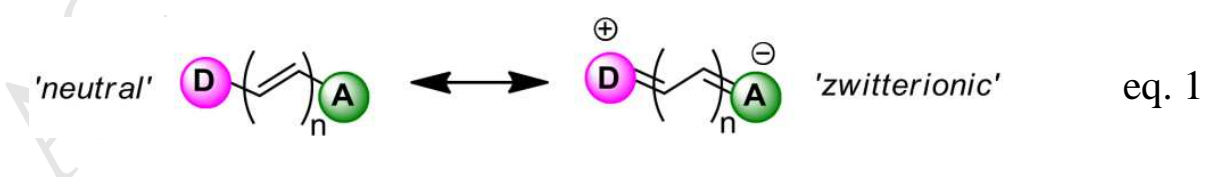

As indicated from NMR experiments in deuterated chloroform, the amount of ground-state ICT is lower for compound $\mathbf{3}$ compared to compound $2 .{ }^{8}$ This lower polarization of $\mathbf{3 d}$, due to the presence of amino group (electron donating) on the methine carbon at the acceptor end, seems to hindering the reaction pathway B. In contrast, the amino group after converted to 
phthalimide, as in $\mathbf{2 d}$, behaves as a strong electron withdrawing (polar, polarizable) group favoring strong ICT, and hence making $\mathbf{2 d}$ a strong dipole in the ground state. Indeed, it has been shown recently that the compounds $\mathbf{2 c}$ and $\mathbf{2 d}$ possess remarkable dipole moment (typically larger than $21 \mathrm{D}$ ) and display a typical cyanine behavior (BLA $\cong 0$ and narrow absorption bands with a marked vinylenic shift of $110 \mathrm{~nm}) .{ }^{8}$ Hence, the compounds $2 \mathbf{c}-\mathbf{d}$ obtained from 3c-d has equal contributions from both the forms ( $\mathbf{N}$ and $\mathbf{Z I})$ and consequently large ground-state dipole moment (as the amount of ICT in the ground state $\rho$ is then 0.5 ). Based on the above investigation and experimental results, we have hereby proposed the mechanism (Scheme 2) for the formation of 1c starting from 2c favored by the much larger dipole moment of 2c. We believe that formation of diarylethene derivative 1c occurs via a thermal isomerization of $\mathbf{2 c}$ followed by the intramolecular 6-exo-trig cyclization that arises due to a nucleophilic attack of the terminal dicyanomethine carbon (induced by the strong dipolar nature) onto the electrophilic C3-methine carbon of the polyenic backbone leading to a six-membered cyclohexadiene system (Scheme 2). This, in presence of triethylamine (base) loses $\mathrm{HCN}$ for attaining aromaticity resulting in substituted phenylthienylethylene derivative. This intramolecular cyclization reaction appears to be highly promoted due to the strong dipolar (cyanine-type) nature of the polar and polarizable chromophores $\mathbf{3}$, facile formation of the six-membered cycle that leads to aromatization (energetically favorable process due to resonance stabilization) via a base-mediated elimination of $\mathrm{HCN}$. The presence of two aromatic units (as opposed to one aromatic unit and a polyenic chain, in $\mathbf{2} \mathbf{c} / \mathbf{2 d}$ ) connected through a $\pi$-bridge in the resultant diarylethylene derivative $\mathbf{1 c} / \mathbf{1 d}$ may provide increased stability (stabilization energy) to the system. Such intramolecular cyclization is unforeseen and is a case of novel observation in extended strong pull-pull polyenic systems. Though shortening of conjugation length in cyanines has been reported some time ago, the mechanism of such degradation is still not clear. ${ }^{2 \mathrm{e}}$ 
It is noteworthy to mention that the intramolecular cyclization is facilitated only when the number of ethylenic linkages between the donor and acceptor is greater than one, i.e., $\mathrm{n}>$ 1. For the shorter push-pull chromophores $(\mathrm{n} \leq 1)$, under the similar reaction conditions, such cyclized products were hardly observed. It is logical to understand that the polyenic backbone with $n>1$ is more flexible to undergo intramolecular cyclization via a six-membered cyclic transition state than when the backbone is with $\mathrm{n} \leq 1$; indeed, the length of the polyenic chain plays a pivotal role for the intramolecular cyclization to happen.

As mentioned earlier, not only the donor and acceptor strength, but also the length of the polyenic chain in a push-pull chromophore determines the performance of a NLO material. The above results could also offer important insights about the mechanism of degradation of such strong push-pull polyenic chromophoric systems during process/fabrication in devices.

\subsection{Optical properties}

In order to investigate the effect of cyclization on the ICT transition, UV-vis absorption measurements were performed in dilute chloroform solutions (ca. $10^{-5} \mathrm{M}$ ) on cyclized derivatives 1c,d and compared to the absorption data of their precursor products $\mathbf{2 c , d}$ which have been reported earlier ${ }^{8}$ as well as with derivative $\mathbf{2 a}$ having the same number of conjugated double bond in the polyenic linker as $\mathbf{1 d}$ (i.e. $m=p=2$ ). The absorption spectrum for 1c,d is displayed in Figure 2 and their absorption characteristics are summarized in Table 2 along with the results of time-dependent (TD) DFT calculations. As expected, these compounds showed a broad and intense absorption band in the visible region of the absorption spectrum $(400-670 \mathrm{~nm})$ characteristic of an ICT transition. As is evident from Figure 2, the low-energy absorption band of $\mathbf{1 d}\left(\lambda_{\max }=551 \mathrm{~nm}\right)$ is red-shifted $($ ca. $25 \mathrm{~nm})$ in agreement with increased conjugation length and broadened compared to that of $\mathbf{1 c}\left(\lambda_{\max }=\right.$ 
$526 \mathrm{~nm})$. Although transition energies calculated at the CAM-B3LYP/6-311+G(d) level are overestimated compared to experiments, the TDDFT calculations are consistent with UV-vis absorption measurements, the absorption maximum of $1 \mathbf{d}$ being red-shifted by $43 \mathrm{~nm}$ with respect to 1c. In addition, the maximum molar extinction coefficient value is found to slightly decrease upon increasing the length $(\mathbf{1 c} \rightarrow \mathbf{1 d})$. Nevertheless, the oscillatory strength is found to increase as a result of the increase in the absorption width with increasing length (Table 2). Note that this trend is qualitatively reproduced by the calculated oscillator strengths, which increase from 1.54 to 2.02 from $\mathbf{1 c}$ to $\mathbf{1 d}$. In conclusion, compounds $\mathbf{1}$ show a very different absorption behavior from that of series $\mathbf{2}$ whose members exhibit very narrow absorption bands - typical of a cyanine like behavior (Table 2) - as well as narrowing of the low-energy absorption band with increasing length. ${ }^{8}$ Additionally, it is important to state that the absorption spectrum of 1c-d shows a huge blue-shift (ca. 277-365 nm) when compared to their linear polyene precursors $\mathbf{2 c - d}$. This is consistent with a reduction of conjugation subsequent to aromatic cyclization. We also observed that the molar extinction coefficients of derivatives $\mathbf{1}$ are much lower than those of the direct condensation products (2). These features are well reproduced by quantum chemical calculations, which predict a spectral blueshift of 200-240 $\mathrm{nm}$ as well as a significant decrease of the oscillator strengths when going from 2c-d to 1c-d. These results further evidence a reduced conjugation behavior and consequently reduced ICT (i.e. $\rho<0.5$ ) and increased BLA in cyclized derivatives $\mathbf{1}$, when compared to the linear derivatives $\mathbf{2}$. The lower ICT in compounds $\mathbf{1 c - d}$ compared to $\mathbf{2 c - d}$ is also evidenced by the much smaller values of ground-state dipole moments (Table 2). In addition, derivatives 1 exhibit very large photo-induced change of dipole moment $(\Delta \mu)$, whereas, as previously reported ${ }^{8}, \Delta \mu$ is negligibly small and vanishing for linear derivatives 2. From the analysis of the total electron densities of the ground and excited electronic states, $\Delta \mu$ can be decomposed as $\Delta \mu=q^{C T} \times d^{C T}$, where $q^{C T}$ is the global amount of charge transferred 
upon light excitation, and $d^{C T}$ is the distance over which this charge is transferred. ${ }^{11}$ The $q^{C T}$ and $d^{C T}$ values reported in Table 1 evidence that the increase of $\Delta \mu$ from $\mathbf{2 c - d}$ to $\mathbf{1 c}-\mathbf{d}$ is due both to a slight enhancement of the photo-induced charge transfer, and to a large increase of the charge transfer distance.

\subsection{Hyper-Rayleigh scattering measurements}

In order to derive $\beta$ values for the novel cyclized systems 1c-d, hyper-Rayleigh scattering (HRS) experiments were performed on the solutions of 1c,d in chloroform under high dilutions (ca. $10^{-5}$ to $10^{-6} \mathrm{M}$ ) in order to avoid effects of aggregation due to intermolecular interaction. The HRS experiments for 1 were conducted at $1907 \mathrm{~nm}$ - i.e. far away from its two-photon resonance - and the quadratic hyperpolarizability values $\beta$ are given in Table 3 together with results of quantum chemical calculations. The novel cyclized push-pull chromophores 1c and 1d show $\beta$ values of $39 \times 10^{-30}$ esu and $74 \times 10^{-30}$ esu, respectively. It is interesting to state that the additional double bond in $\mathbf{1 d}$ provided a ca. 2 -fold increase in the value of first order hyperpolarizability as that of 1c, which is well reproduced by TD-DFT calculations, where the $\beta(\mathbf{1 d}) / \beta(\mathbf{1 c})$ ratio amounts to 2.18 . As observed from Table 3 , compounds 1c,d show much smaller $\beta$ values than their elongated precursors $\mathbf{2 c}, \mathbf{d}$ which show very large resonance enhancement in relation with their cyanine-like behavior. However, when comparing the $\beta$ values of compounds $\mathbf{1 d}$ and $\mathbf{2 a}$ having the same number of double bonds (i.e., $\mathrm{m}=\mathrm{p}=2$ ) and absorbing in the same spectral region, we observed that diene 1d shows a $60 \%$ larger $\beta$ value than diene 2 a though being slightly blue-shifted. This observation is consistent with the classical picture in terms of BLA $/ \beta$ response relationship as 1d shows intermediate BLA value ( $\Delta J$ close to optimum value of $3 \mathrm{~Hz})^{2 \mathrm{a}}$ whereas $2 \mathrm{a}$ has vanishing BLA. ${ }^{8}$ In addition to the theoretical $\beta_{\mathrm{HRS}}$ values $\left(\beta_{H R S}^{\text {calc }}\right)$, Table 3 also reports the main diagonal component of the $\beta$ tensor, $\beta_{z z z}$ (with $z$ defined as the charge transfer axis 
parallel to the poly[n]enic backbone, see Chart 2) as well as the depolarization ratio (DR) calculated at the CAM-B3LYP/6-311G(d) level. DR gives information on the symmetry of the molecular part responsible for the HRS signal. In the case of ideal 1-dimensional (1D) push-pull chromophores, for which $\beta_{z z z}$ is the only non-vanishing component of the $\beta$ tensor, $\mathrm{DR}=5 .^{12}$ Moreover, for those ideal 1D systems, $\beta_{z Z Z}^{1 D}=\sqrt{35 / 6} \beta_{H R S}$. Thus, the $\beta_{z Z z} / \beta_{z Z Z}^{1 D}$ ratios, gathered in Table 3, measure the deviation from the ideal $1 \mathrm{D}$ case of the NLO responses of the various chromophores.

As expected for $\pi$-conjugated push-pull molecules having a strong dipole moment in their electronic ground state, the $\beta_{\mathrm{zzz}}$ component largely dominates the HRS responses of derivatives $\mathbf{1}$ and 2. The strong $1 \mathrm{D}$ nature of the NLO responses is further confirmed by the DR values, all close to 5 . From 1c to $\mathbf{1 d}$, as well as within the $\mathbf{2 a - d}$ series, the increase of the conjugation length reinforces the 1D character of the NLO response, as indicated by the progressive increase of the DR values and of the $\beta_{z z z} / \beta_{z z z}^{1 D}$ ratios. Surprisingly, the calculations predict a stronger 1D character for the cyclized derivatives 1c-d than for their linear precursors $\mathbf{2 c - d}$.

\subsection{Thermal properties}

It is known that conjugated push-pull chromophores with elongated polyenic $\pi$-spacers may lead to very large non-linear responses. ${ }^{2}$ However, one of the prime concerns for them to be considered for use as suitable non-linear optical materials in electro-optic devices, is their

chemical and thermal stability. ${ }^{13}$ Having studied the chemical degradation under basic conditions of these systems, we started to estimate the thermal stability, i.e., thermal decomposition temperature $\left(T_{\mathrm{d}}\right)$, of $\mathbf{1}$ by thermogravimetric analysis (TGA) under the argon gas atmosphere. The $T_{\mathrm{d}}$ values are provided in Table 3 . All the cyclized products showed thermal decomposition temperature beyond $250{ }^{\circ} \mathrm{C}$, which is quite attractive. Indeed 
arylphenylethylene derivatives 1c-d thus exhibit higher thermal stabilities than their linear poly[n]ene counterparts 2 . This increased thermal stability can be ascribed to the cyclization. Indeed, it has been reported earlier that stilbene-type push-pull derivatives exhibit higher thermal stabilities than linear polyenic analogues of equal length. ${ }^{3 a}$ It has also been realized that incorporation of an aromatic/heteroaromatic ring in the polyenic chain would improve their stability, thanks to the effect of aromaticity of the ring which is expected to lower the energy level of the HOMO, thus making it more difficult to undergo oxidation or chemical degradation. $^{3 \mathrm{~b}}$

\section{Conclusions}

The present study has demonstrated that elongated merocyanine dyes bearing three cyano and one phthalimido electron-withdrawing substituents at one end may undergo intramolecular cyclization under basic conditions. The terminal triene moiety bearing the three cyano substituents and a phthalimide unit undergoes cyclization followed by aromatization (in relation with $\mathrm{HCN}$ elimination). This base-promoted reaction yields new magenta dyes having a phenyl terminal ring bearing two cyano and one phthalimido substituents. We believe that this unprecedented reaction is favored by the large dipole moment (i.e. $\geq 21$ D) of their elongated merocyanine precursors. As expected from the reduction in the polyenic chain length and number of cyano substituents, these dyes show improved transparency in the visible region (resulting from a marked major hypsochromic and hypochromic shift of the absorption band) as compared to their merocyanine precursors. In addition their nonlinear response $\beta$ (quadratic polarizability) is found to be larger than the merocyanine dyes having the same number of double bonds in the polyenic system while their thermal stability is improved. As such, these novel short derivatives represent promising new dyes with improved nonlinearity/stability/transparency properties, to serve as materials for 
nonlinear optics. This also opens new directions for the design of probes for nonlinear bioimaging. ${ }^{14}$

\section{Acknowledgements}

MBD and PKD thank the Indo-French Centre for Promotion of Advanced Research (IFCPAR)/Centre Franco-Indien pour la Promotion de la Recherche Avancée (CEFIPRA) for financial support, and a PDF to VP. MBD gratefully acknowledges financial support from Conseil Régional d'Aquitaine (Chaire d'accueil grant). FC thanks Dr. V. Liégeois for helpful discussions. The calculations were performed on the "Mésocentre de Calcul Intensif Aquitain" (MCIA) of the University of Bordeaux, financed by the Conseil Régional d'Aquitaine and the French Ministry of Research and Technology.

\section{Experimental section}

\subsection{General aspects}

All reactions were carried out under argon. Solvents were generally dried and distilled prior to use. Reactions were monitored by TLC on Merck 60 F254 aluminum sheets precoated with silica gel. Column chromatography was performed using Merck silica gel Si 60 (40-63 mm, 230-400 mesh), unless otherwise noted. NMR studies were carried out by Bruker Avance AV $300\left({ }^{1} \mathrm{H}: 300.13 \mathrm{MHz},{ }^{13} \mathrm{C}: 75.48 \mathrm{MHz}\right)$ or Bruker AV $500\left({ }^{1} \mathrm{H}: 500.13 \mathrm{MHz}\right.$,

${ }^{13} \mathrm{C}: 125.47 \mathrm{MHz}$ )high performance digital FTNMR spectrometer in $\mathrm{CDCl}_{3}$ solutions; ${ }^{1} \mathrm{H}$ chemical shifts are given in ppm relative to TMS as internal standard, $J$ values in $\mathrm{Hz}$, and ${ }^{13} \mathrm{C}$ chemical shifts relative to the central peak of $\mathrm{CDCl}_{3}$ at $77.0 \mathrm{ppm}$. Infrared spectroscopic studies were performed on neat solids on a Perkin-Elmer Spectrum 100 ATR instrument. High-resolution mass spectra (HRMS) were recorded at the Centre Régional de Mesures Physiques de l'Ouest (C.R.M.P.O., Rennes), using a Micromass MS/MS ZABSpec TOF 
instrument with EBE TOF geometry; liquid secondary ion mass spectrometry (LSIMS) was performed at $8 \mathrm{kV}$ with $\mathrm{Cs}^{+}$in $m$-nitrobenzyl alcohol (mNBA). UV-Vis absorption spectra were recorded on a Jasco V-570 UV-vis spectrophotometer at ambient temperature; solvents used were of spectroscopic grade. The first hyperpolarisabilities $\beta$ of the compounds were measured at $1907 \mathrm{~nm}$ by using the hyper-Rayleigh scattering technique in solution, as described in our previous report. ${ }^{8,15}$ Thermal stabilities were estimated on a Perkin Elmer thermal gravimetric analyzer under a flow of nitrogen gas at a heating rate of $10{ }^{\circ} \mathrm{C}$ per minute.

\subsection{Synthesis of push-pull dyes.}

While the synthetic procedure for the preparation of 2, 3a-d has been reported earlier from our laboratory, ${ }^{8}$ the general procedure for the preparation of $\mathbf{1 b}, \mathbf{c}$ and $\mathbf{4 b}$ is given below

\subsubsection{General procedure for the preparation of $1 \mathrm{c}$.}

The typical procedure for the preparation of $\mathbf{1 c}$ is as follows: to a well stirred solution of the mixture of chromophore (0.44 mmol, 1.0 equiv.) and phthalic anhydride $(1.32 \mathrm{mmol}$, 3.0 equiv. $)$ in dry dichloromethane $(12.0 \mathrm{~mL})$ was introduced triethylamine $(1.32 \mathrm{mmol}, 3.0$ equiv.) under argon gas atmosphere. The reaction mixture was heated at $50{ }^{\circ} \mathrm{C}$ for a period of $5 \mathrm{~h}$. The reaction was monitored by TLC from time to time. After appropriate reaction time, the reaction mixture was concentrated at the rotary evaporator and the resulting crude residue was subjected to silica-gel column chromatography using $100 \%$ dichloromethane as the eluent. The fractions were combined, evaporated and dried to afford the by-product 1c along with the direct condensation products in isolable yields. 


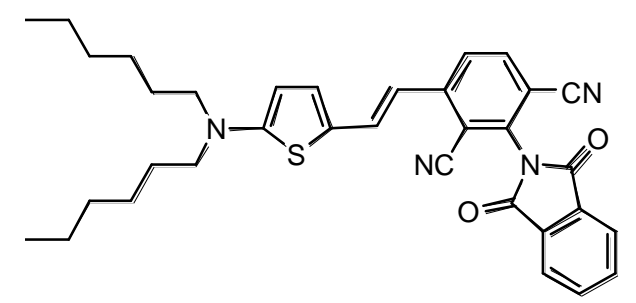

1c: Yield 16\%; IR (neat) 2926, 2857, 2228, 1790, 1732, 1610, 1579, 1497, 1433, 1362, 1225 $\mathrm{cm}^{-1} ;{ }^{1} \mathrm{H}$ NMR $\left(500.13 \mathrm{MHz}, \mathrm{CDCl}_{3}\right) \delta 0.90(\mathrm{t}, 6 \mathrm{H}, J=6.0 \mathrm{~Hz}), 1.33(\mathrm{bs}, 12 \mathrm{H}), 1.65(\mathrm{~m}, 4 \mathrm{H})$, $3.30(\mathrm{t}, 4 \mathrm{H}, J=7.5 \mathrm{~Hz}), 5.78\left(\mathrm{~d}, 1 \mathrm{H}, \mathrm{H}_{\alpha}, J_{\alpha \beta}=4.0 \mathrm{~Hz}\right), 6.61\left(\mathrm{~d}, 1 \mathrm{H}, J_{\mathrm{AX}}=15.5 \mathrm{~Hz}\right), 7.00(\mathrm{~d}$, $\left.1 \mathrm{H}, \mathrm{H}_{\beta}, J_{\alpha \beta}=4.0 \mathrm{~Hz}\right), 7.47\left(\mathrm{~d}, 1 \mathrm{H}, J_{\mathrm{AX}}=15.5 \mathrm{~Hz}\right), 7.73\left(\mathrm{~d}, 1 \mathrm{H}, J_{\mathrm{AB}}=8.5 \mathrm{~Hz}\right), 7.77(\mathrm{~d}, 1 \mathrm{H}$, $\left.J_{\mathrm{AB}}=8.5 \mathrm{~Hz}\right), 7.86\left(\mathrm{AA}^{\prime} \mathrm{XX}, 2 \mathrm{H}\right), 8.03\left(\mathrm{AA}^{\prime} \mathrm{XX}, 2 \mathrm{H}\right) ;{ }^{13} \mathrm{C} \mathrm{NMR}\left(75.47 \mathrm{MHz}, \mathrm{CDCl}_{3}\right) \delta$ $14.0,22.6,26.6,27.0,31.5,53.7,101.9,108.5,110.5,112.5,114.1,115.2,123.1,123.8$, 124.6, 131.6, 132.1, 134.9, 135.0, 135.1, 138.8, 147.7, 161.7, 165.2; HRMS (LSIMS ${ }^{+}$, mNBA) calcd for $\mathrm{C}_{34} \mathrm{H}_{36} \mathrm{~N}_{4} \mathrm{O}_{2} \mathrm{~S}(\mathrm{M}+\mathrm{H})^{+} m / z$ 565.2637, found 565.2631. Elemental analysis (\%) for $\mathrm{C}_{34} \mathrm{H}_{36} \mathrm{~N}_{4} \mathrm{O}_{2} \mathrm{~S}$ : calcd.: C, 72.31; H, 6.43; N, 9.92; S, 5.67; found: C, 72.01; H, 6.68; N, $9.98 ; S, 5.88$.

\subsubsection{Preparation of $1 d$.}

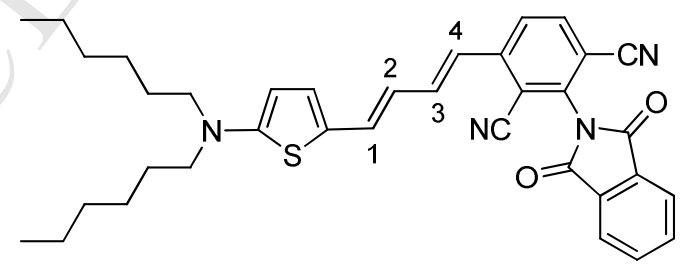

The similar procedure as described for 1c is followed. 1d: Yield 32\%; IR (neat) 2927, 2857, $2229,1851,1733,1570,1528,1429,1358,1257 \mathrm{~cm}^{-1} ;{ }^{1} \mathrm{H}$ NMR $\left(500.13 \mathrm{MHz}, \mathrm{CDCl}_{3}\right) \delta 0.90$ $(\mathrm{t}, 6 \mathrm{H}, J=6.0 \mathrm{~Hz}), 1.32(\mathrm{~m}, 12 \mathrm{H}), 1.64(\mathrm{~m}, 4 \mathrm{H}), 3.27(\mathrm{t}, 4 \mathrm{H}, J=7.5 \mathrm{~Hz}), 5.72\left(\mathrm{~d}, 1 \mathrm{H}, \mathrm{H}_{\alpha}\right.$ 
$\left.J_{\alpha \beta}=4.2 \mathrm{~Hz}\right), 6.39\left(\mathrm{dd}, 1 \mathrm{H}, \mathrm{H}_{2}, J_{23}=11.0 \mathrm{~Hz}, J_{21}=14.8 \mathrm{~Hz}\right), 6.74\left(\mathrm{~d}, 1 \mathrm{H}, \mathrm{H}_{1}, J_{12}=14.8 \mathrm{~Hz}\right)$,

$6.85\left(\mathrm{~d}, 1 \mathrm{H}, \mathrm{H}_{\beta}, J_{\alpha \beta}=4.2 \mathrm{~Hz}\right), 6.91\left(\mathrm{~d}, 1 \mathrm{H}, \mathrm{H}_{4}, J_{43}=14.8 \mathrm{~Hz}\right), 7.23\left(\mathrm{dd}, 1 \mathrm{H}, \mathrm{H}_{3}, J_{32}=11.0\right.$ $\left.\mathrm{Hz}, J_{34}=14.8 \mathrm{~Hz}\right), 7.77\left(\mathrm{~d}, 1 \mathrm{H}, J_{\mathrm{AB}}=8.4 \mathrm{~Hz}\right), 7.80\left(\mathrm{~d}, 1 \mathrm{H}, J_{\mathrm{AB}}=8.4 \mathrm{~Hz}\right), 7.86\left(\mathrm{AA}^{\prime} \mathrm{XX} X^{\prime}\right.$, 2H), 8.03 (AA' XX', 2H); ${ }^{13} \mathrm{C}^{\prime} \mathrm{NMR}\left(75.47 \mathrm{MHz}, \mathrm{CDCl}_{3}\right.$, TMS) $\delta 14.0 ; 22.6 ; 26.7,27.0,31.6$, $53.7,101.5,109.7,111.4,114.0,115.0,120.3,120.5,124.2,124.5,124.6,131.5,132.4,134.0$, 135.0, 135.3, 138.7, 139.5, 147.3, 160.2, 165.1; HRMS (ESI) calcd for $\mathrm{C}_{36} \mathrm{H}_{38} \mathrm{~N}_{4} \mathrm{O}_{2} \mathrm{~S}\left(\mathrm{M}^{+}\right)$ $m / z$ 590.2716, found 590.2713. Elemental analysis (\%) for $\mathrm{C}_{36} \mathrm{H}_{38} \mathrm{~N}_{4} \mathrm{O}_{2} \mathrm{~S}$ : calcd.: C, 73.19; $\mathrm{H}$, 6.48; N, 9.48; S, 5.43; found: C, 72.98; H, 6.58; N, 9.66; S, 5.58.

\subsection{Quantum chemical calculations.}

Molecular structures were optimized at the B3LYP/6-311G(d) level, by replacing the hexyl terminal chains by simpler methyl groups. All structures were optimized without imposing any symmetry constraint, and characterized as real minima of the potential energy surface based on their vibrational frequencies. Vertical excitation energies and excited state properties were determined using time-dependent density functional theory (TDDFT) with the longrange corrected CAM-B3LYP exchange-correlation (XC) functional and the 6-311+G(d) basis set. Dynamic (frequency-dependent) first hyperpolarisabilities were calculated at the same level of approximation, using incident wavelengths of $1907 \mathrm{~nm}$ without assuming Kleinman's conditions. ${ }^{16}$ Solvent effects were included both in geometry optimizations and calculations of the optical properties by using the Integral Equation Formalism (IEF) version of the Polarisable Continuum Model (IEF-PCM). ${ }^{17}$ Quantum chemical calculations were performed using the Gaussian 09 package. ${ }^{18}$ 


\section{References}

1. (a) Dalton LR, Sullivan PA, Bale DH. Electric field poled organic electro-optic materials: state of the art and future prospects. Chem Rev 2010;110; 25-55. (b) Marder SR, Guest Ed. Themed issue on organic nonlinear optics. J Mater Chem 2009; 19; 7381-7568. (c) Kunkel AZ; Lenze MR; Kronenberg NM; Krause AM; Stolte M; Meerholz K; Würthner F. NIR-absorbed merocyanin dyes for BHJ solar cells. Chem Mater 2014; 26; 4856-4866.

2. (a) Marder SR; Cheng LT; Tiemann BG; Friedli AC; Blanchard-Desce M; Perry JW; Skindhoej. Large first hyperpolarizability in push-pull polyenes by tuning of the bond length alternation and aromaticity. Science 1994; 263; 511-514; (b) Blanchard-Desce M; Alain V; Bedworth PV; Marder SR; Fort A; Runser C; Barzoukas M; Lebus V; Wortmann R. Large quadratic hyperpolarizabilities with donar-acceptor polyenes exhibiting optimum bond length alternation: correlation between structure and hyperpolarizability. Chem Eur J 1997; 3; 1091-1104. (c) Alain V; Thouin L; Blanchard-Desce M; Gubler U; Bosshard C; Günter V; Muller J; Fort V; Barzoukas M. Molecular engineering of push-pull phenyl polyenes for nonlinear optics: improved solubility, stability, and nonlinearities. Adv Mater 1999; 11; 1210-1214. (d) Plaquet A; Champagne B; Kulhánek J; Bures F; Bogdan E; Castet F; Ducasse L; Rodriguez V. Effects of the nature and length of the $\pi$-conjugated bridge on the second-order nonlinear optical responses of push-pull molecules including 4,5dicyanoimidazole and their protonated forms. Chem Phys Chem 2011; 12; 3245.

3. (a) Andreu R; Carrasquer L; Franco S; Garín J; Orduna J; Baroja NM; Alicante R; Villacampa B; Allain B. 4H-Pyran-4-ylidenes: strong proaromatic donors for organic nonlinear optical chromophores. J Org Chem 2009; 74; 6647-6657. (b) Baroja NM de; Garín J; Orduna J; Andreu R; Blesa MJ; Villacampa B; Alicante R; Franco S. 
Synthesis, characterization, and optical properties of $4 H$-pyran-4-ylidene donor based chromophores: the relevance of the location of a thiophene ring in the spacer. J Org Chem 2012; 77; 4634-4644. (c) Andreu R; Galan E; Garín J; Herrero V; Lacarra E; Orduna J; Alicante R; Villacampa B. Linear and V-shaped nonlinear optical chromophores with multiple 4H-pyran-4-ylidene moieties. J Org Chem 2010; 75; 1684-1692. (d) Davies JA; Elangovan A; Sullivan PA; Olbricht BC; Bale DH; Ewy TR; Isborn CM; Eichinger BE; Robinson BH; Reid PJ; Li X; Dalton LR. Rational enhancement of second-order nonlinearity: bis-(4-methoxyphenyl)hetero-aryl-amino donor-based chromophores: design, synthesis and electrooptic activity. J Am Chem Soc 2008; 130; 10565-10575. (e) Alías S; Andreu R; Cerdán MA; Franco S; Garín J; Orduna J.; Romero P; Villacampa B. Synthesis, characterization and optical properties of merocyanines derived from malononitrile dimer. Tetrahedron Lett 2007; 48; 65396542. (f) Jang S-H; Luo J; Tucker NM; Leclercq A; Zojer E; Haller MA; Kim TD; Kang J-W; Firestone K; Bale D; Lao D; Benedict JB; Cohen D; Kaminsky W; Kahr B; Brédas JL; Reid P; Dalton LR; Jen AK-Y. Pyrroline chromophores for electro-optics. Chem Mater 2006; 18; 2982-2988.

4. Spangler CW; McCoy V. Preparation of conjugated aromatic polyenals by Wittig oxopropenylation. Synth Commun 1998;18; 51-59.

5. Andreu R; Carrasquer L; Cerdán MA; Fernández A; Franco S; Garín J; Orduna J. A simple synthesis of 2-methyl-1,3-dithiolium and related cations. Synlett 2007; 1470 1472.

6. (a) Wolf JJ; Wortmann R. Organic materials for second-order non-linear optics. Adv Phys Org Chem 1999; 32; 121-217. (b) Suponitsky KY; Timofeeva TV; Antipin MY. Molecular and crystal design of nonlinear optical organic materials. Russ Chem Rev $2006 ; 75 ; 457-496$. 
7. (a) Vanmaele LJ. New dyes derived from malononitrile dimer. Tetrahedron Lett 1992; 33; 961-964. (b) Reidlinger C; Dworczak R; Junek H. Fischer's base as an electron donor for new penta- and heptamethines. Dyes Pigments 2000; 44; 219-226. (c) Fatiadi AJ. New applications of malononitrile in organic chemistry. Synthesis 1978; 165-204. (d) Freeman F. The chemistry of malononitrile. Chemical Rev 1969; 69; 591-624. (d) Bardasov IN; Mihailov DL; Alekseeva AU; Ershov OV; Nasakin OE. Heterocyclization of arylmethylidene derivatives of malononitrile dimer: synthesis of 4-amino-6-aryl -2-halopyridine-3,5-dicarbonitriles. Tetrahedron Lett 2013; 54; 21-22.

8. Parthasarathy V; Pandey R; Stolte M; Ghosh S; Castet F; Würthner F; Das PK;

Blanchard-Desce M. Combination of cyanine behavior and giant hyperpolarizability in novel merocyanine dyes: beyond the bond length alternation (BLA) paradigm. Chem Eur J 2015; 21; 14211-14217.

9. Khan MN; Fleury J-P; Baumlin P; Hubschwerlen C. A new route to trinuclear carbocyanines. Tetrahedron $1985 ; 41 ; 5341-5345$.

10. Oudar JL; Chemla V. Hyperpolarizabilities of the nitroanilines and their relations to the excited state dipole moment. J Chem Phys 1977; 66; 2664-2668.

11. (a) Bahers T Le; Adamo C ; Ciofini I. A qualitative index of spatial extent in chargetransfer excitations. J Chem Theory Comput 2011; 7; 2498-2506; (b) Jacquemin D; Bahers T Le; Adamo C; Ciofini I. What is the "best" atomic charge model to describe through-space charge-transfer excitations? Phys Chem Chem Phys 2012; 14; $5383-$ 5388.

12. (a) Brasselet S; Zyss J. Multipolar molecules and multipolar fields: probing and controlling the tensurial nature of nonlinear media. J Opt Soc Am B 1998; 15; 25. (b) Castet F; Bogdan E; Plaquet L; Ducasse B; Champagne V; Rodriguez V. Reference molecules for nonlinear optics: A joint experimental and theoretical investigation. $\mathrm{J}$ 
Chem Phys 2012, 136, 024506.

13. Benight SJ; Bale DH; Olbricht BC; Dalton LR. Organic electro-optics: understanding material structure/function relationships and device fabrication issues. J Mater Chem $2009 ; 19 ; 7466-7475$.

14. López-Duarte I; Chairatana P; Wu Y; Pérez-Moreno J; Bennett PM; Reeve J E; Boczarow I; Kaluza W; Hosny NA; Stranks SD; Nicholas RJ; Clays K; Kuimova MK; Anderson HL. Thiophene-based dyes for probing membranes. Org Biomol Chem $2015 ; 13 ; 3792-3802$.

15. Venkatakrishnan P; Pandey R; Terenziani F; Das PK; Blanchard-Desce M. Combined transparency and optical nonlinearity enhancement in flexible covalent multimers by operating through-space interactions between dipolar chromophores. Phys Chem Chem Phys 2014; 16; 9096-9103.

16. Bersohn R; Pao YH; Frisch HL. Double-quantum light scattering by molecules. J Chem Phys 1966; 45; 3184.

17. (a) Tomasi J; Persico M. Molecular interactions in solution: an overview of methods based on continuous distributions of the solvent. Chem Rev 1994; 94; 2027. (b) Tomasi J; Mennucci B; Cammi R. Quantum mechanical continuum solvation models. Chem Rev 2005; 105; 2999.

18. Gaussian 09, Revision D.01, M. J. Frisch et al. Gaussian, Inc., Wallingford CT, 2009. 
Table 1. Relative Gibbs free enthalpies $\left(\boldsymbol{\Delta G}, \mathrm{kcal} . \mathrm{mol}^{-1}\right)$, torsion angles $\left(\boldsymbol{\theta}_{1}\right.$ and $\boldsymbol{\theta}_{2}$, degrees $)$, and bond length alternation (BLA, $\AA$ ) along the conjugated linker for the four rotamers of compounds 1c-d, as optimized at the B3LYP/6-311G(d) level in chloroform. The BLA for derivatives of series $2^{8}$ have been added for the sake of comparison.

\begin{tabular}{crrrr}
\hline $\mathbf{c p d}$ & $\boldsymbol{\Delta} \mathbf{G}$ & $\boldsymbol{\theta}_{\mathbf{1}}$ & $\boldsymbol{\theta}_{\mathbf{2}}$ & $\mathbf{B L A}$ \\
\hline $\mathbf{1 c}(\mathrm{m}=1)$ & 0.00 & 179.5 & 179.4 & -0.0648 \\
$\mathbf{1 c}(\mathrm{m}=1)$ & 2.05 & 0.0 & 178.8 & -0.0678 \\
$\mathbf{1 c}(\mathrm{m}=1)$ & 3.92 & $-0,04$ & -6.8 & -0.0685 \\
$\mathbf{1 c}(\mathrm{m}=1)$ & 2.17 & 179.1 & -4.4 & -0.0651 \\
$\mathbf{1 d}(\mathrm{m}=2)$ & 0.00 & 179.6 & 178.9 & -0.0594 \\
$\mathbf{1 d}(\mathrm{m}=2)$ & 1.73 & 0.4 & 179.0 & -0.0601 \\
$\mathbf{1 d}(\mathrm{m}=2)$ & 3.74 & -0.3 & -6.3 & -0.0609 \\
$\mathbf{1 d}(\mathrm{m}=2)$ & 3.58 & 179.5 & -0.7 & -0.0598 \\
\hline $\mathbf{2 a}(\mathrm{n}=0)$ & $/$ & $/$ & $/$ & 0.0098 \\
$\mathbf{2 b}(\mathrm{n}=1)$ & $/$ & $/$ & $/$ & 0.0043 \\
$\mathbf{2 c}(\mathrm{n}=2)$ & $/$ & $/$ & $/$ & 0.0004 \\
$\mathbf{2 d}(\mathrm{n}=3)$ & $/$ & $/$ & $/$ & -0.0023 \\
\hline
\end{tabular}

Table 2. Maximum absorption wavelengths $\left(\lambda_{\max }, \mathrm{nm}\right)$, molar extinction coefficients $\left(\varepsilon_{\max }\right.$, $\mathrm{M}^{-1} \cdot \mathrm{cm}^{-1}$ ), and full-widths at half-maximum (FWHM, $\mathrm{cm}^{-1}$ ) measured in chloroform for compounds 1c and 1d. Transition wavelengths $\left(\lambda_{\mathrm{ge}}, \mathrm{nm}\right)$, oscillator strengths $\left(f_{g e}\right)$, ground- and excited-state dipole moments $\left(\mu_{\mathrm{g}}\right.$ and $\left.\mu_{\mathrm{e}}, \mathrm{D}\right)$, dipole moment variation $\left(\Delta \mu=\left|\overrightarrow{\mu_{e}}-\overrightarrow{\mu_{g}}\right|, \mathrm{D}\right)$, charge transferred $\left(q^{C T}, \mid \mathrm{e}\right)$ ) and charge transfer distance $\left(d^{C T}, \AA\right)$, calculated for the $\mathrm{S}_{0} \rightarrow \mathrm{S}_{1}$ transition at the CAM-B3LYP/6-311+G(d) level. Data for derivatives of series $\mathbf{2}^{8}$ have been added for the sake of comparison.

\begin{tabular}{cccccccccccc}
\hline Compd. & $\lambda_{\max }$ & $\boldsymbol{\varepsilon}_{\max }$ & $\mathbf{F W H M}$ & $\boldsymbol{\varepsilon}_{\max } \mathbf{F W H M}$ & $\boldsymbol{\lambda}_{\text {ge }}$ & $\boldsymbol{f}_{\mathrm{ge}}$ & $\boldsymbol{\mu}_{\mathrm{g}}$ & $\boldsymbol{\mu}_{e}$ & $\boldsymbol{\Delta} \boldsymbol{\mu}$ & $\boldsymbol{q}^{C T}$ & $\boldsymbol{d}^{C T}$ \\
\hline $\mathbf{1 c}(\mathrm{m}=1)$ & 526 & $4.510^{4}$ & 2850 & $1.2810^{8}$ & 474 & 1.54 & 10.66 & 19.78 & 9.15 & 0.59 & 3.22 \\
$\mathbf{1 d}(\mathrm{m}=2)$ & 551 & $4.0710^{4}$ & 3850 & $1.5710^{8}$ & 517 & 2.02 & 12.08 & 24.16 & 12.08 & 0.63 & 3.99 \\
\hline $\mathbf{2 a}(\mathrm{p}=2)$ & 581 & $1.1210^{5}$ & 1300 & $1.4610^{8}$ & 508 & 1.19 & 15.24 & 17.00 & 1.84 & 0.45 & 0.86 \\
$\mathbf{2 b}(\mathrm{p}=3)$ & 690 & $1.710^{5}$ & 900 & $1.5310^{8}$ & 593 & 1.73 & 20.56 & 21.74 & 1.33 & 0.45 & 0.62 \\
$\mathbf{2 c}(\mathrm{p}=4)$ & 803 & $2.610^{5}$ & 830 & $2.1610^{8}$ & 675 & 2.25 & 25.27 & 26.86 & 1.78 & 0.47 & 0.79 \\
$\mathbf{2 d}(\mathrm{p}=5)$ & 916 & $2.310^{5}$ & 800 & $1.8410^{8}$ & 756 & 2.77 & 29.76 & 32.32 & 2.67 & 0.49 & 1.14 \\
\hline
\end{tabular}


Table 3. HRS and thermal stability data of compounds 1c and 1d. Data for derivatives of series $2^{8}$ have been added for the sake of comparison. All $\beta$ values are given in $10^{-30}$ esu. $T_{\mathrm{d}}$ values are in ${ }^{\circ} \mathrm{C}$.

\begin{tabular}{ccccccc}
\hline Compd. & $\beta_{H R S}^{\text {exp }(a)}$ & $\beta_{H R S}^{\text {calc }}(b)$ & $\mathrm{DR}^{(b)}$ & $\beta_{\mathrm{ZZZ}}{ }^{(b)}$ & $\beta_{\mathrm{ZZZ}} / \beta_{\mathrm{ZZZ}}^{1 D(c)}$ & $T_{\mathrm{d}}{ }^{(d)}$ \\
\hline $\mathbf{1 c}(\mathrm{m}=1)$ & 39 & 167 & 4.87 & 386 & 96 & 264 \\
$\mathbf{1 d}(\mathrm{m}=2)$ & 74 & 364 & 4.94 & 853 & 97 & 286 \\
\hline $\mathbf{2 a}(\mathrm{p}=2)$ & 47 & 52 & 4.11 & 92 & 72 & 269 \\
$\mathbf{2 b}(\mathrm{p}=3)$ & 78 & 102 & 4.11 & 176 & 72 & 254 \\
$\mathbf{2 c}(\mathrm{p}=4)$ & 630 & 235 & 4.32 & 441 & 78 & 215 \\
$\mathbf{2 d}(\mathrm{p}=5)$ & 3900 & 611 & 4.59 & 1272 & 86 & 210 \\
\hline
\end{tabular}

(a) $\beta$ value derived from HRS measurements conducted at $1.907 \mu \mathrm{m}$ in chloroform. ${ }^{\left({ }^{b)}\right.}$ values calculated at the CAM-B3LYP/6-311G(d) level in chloroform. ${ }^{(c)}$ values given in \%, with $\beta_{Z Z Z}^{1 D}=\sqrt{35 / 6} \beta_{H R S}^{\text {calc }}{ }^{(d)}$ measured using TGA under nitrogen gas atmosphere at a heating rate of $5{ }^{\circ} \mathrm{C}$ per minute. 


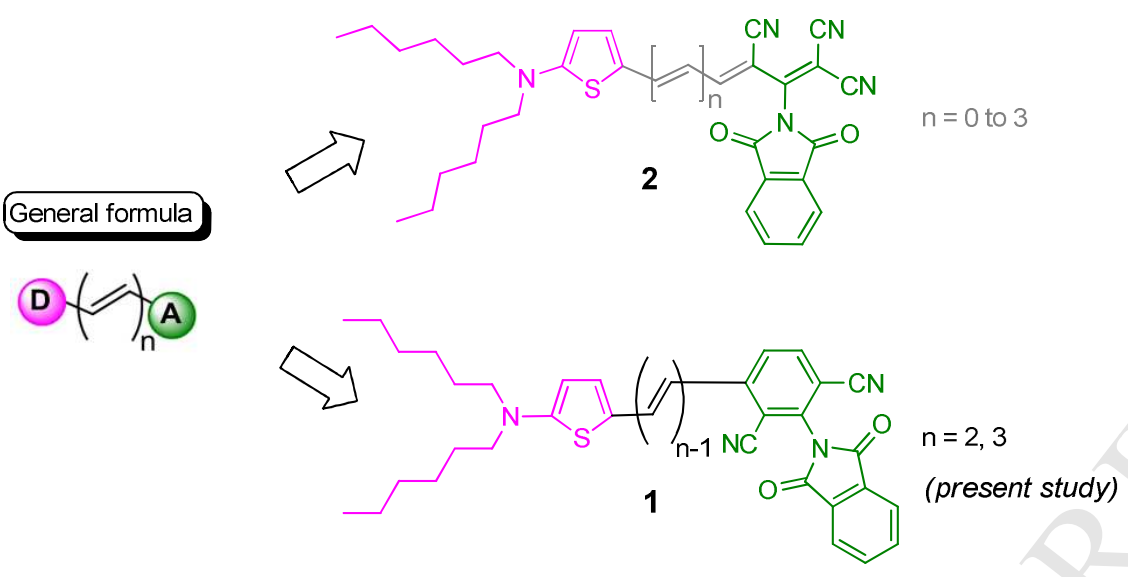

Chart 1. General formula for the chemical structures of push-pull systems $\mathbf{1}$ and $\mathbf{2}$.
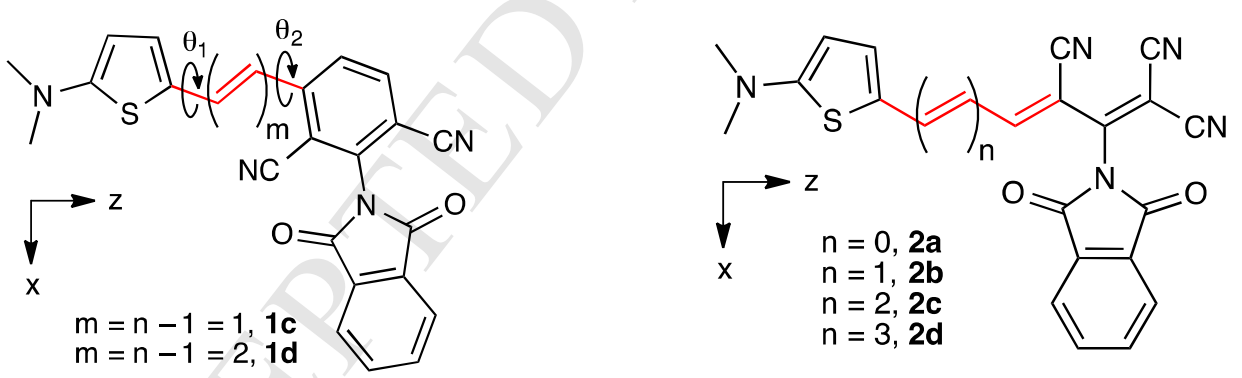

Chart 2: Push-pull polyenic chromophores 1 and 2, with for compound 1 the torsional angles $\theta_{1}=\mathrm{S}-\mathrm{C}-\mathrm{C}-\mathrm{H}$ and $\theta_{2}=\mathrm{C}-\mathrm{C}-\mathrm{C}-\mathrm{C}_{\mathrm{CN}}$. In red, the conjugated segment considered for the calculation of the BLA (defined as the average of the differences in length of consecutive double and single carbon-carbon bonds along this segment). Cartesian frames used in the NLO calculations are also displayed. $N, N$-Dimethylaminothiophene was used in order to simplify the calculation. 


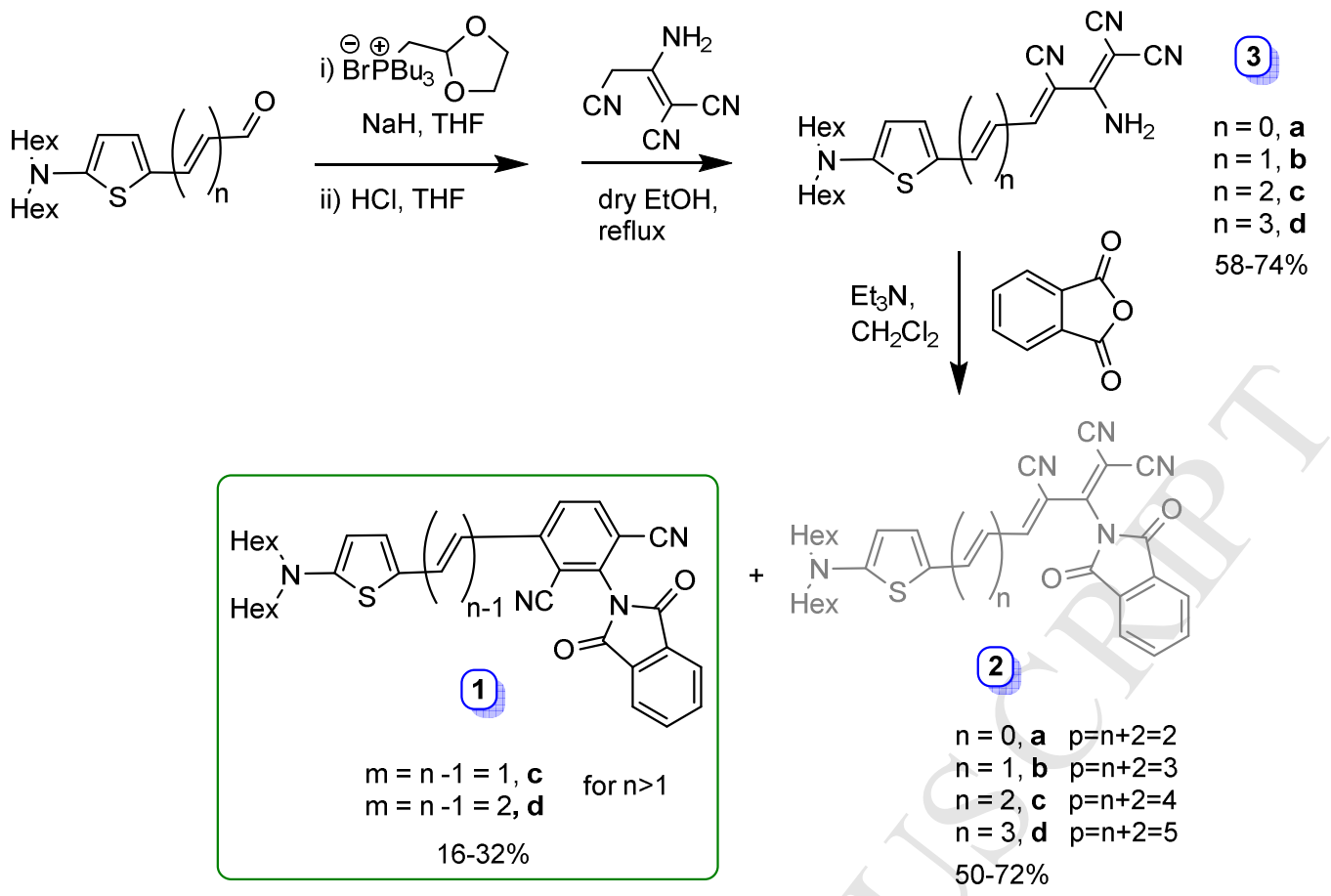

Scheme 1. Preparation of the push-pull polyenic chromophores 1-3.

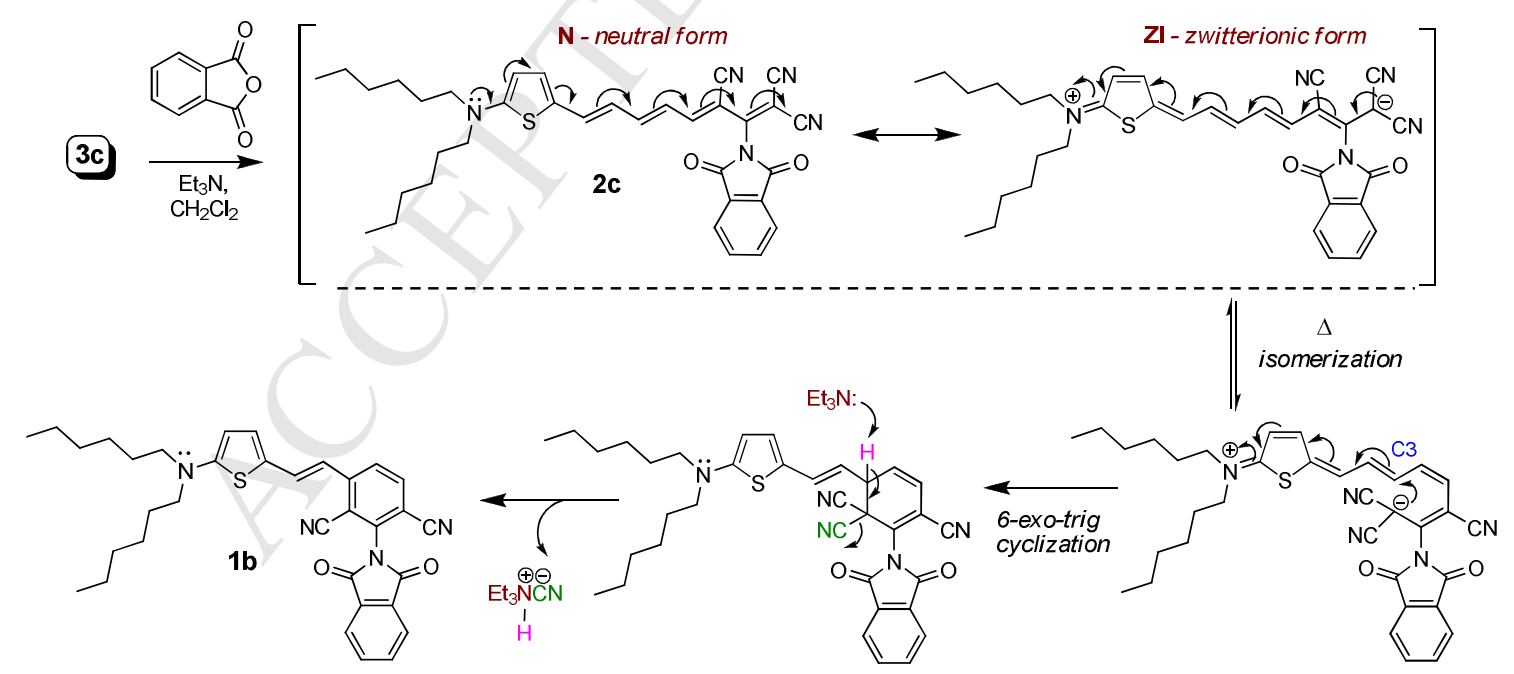

Scheme 2. Proposed mechanism for the formation of $1 \mathbf{c}$ from $3 \mathbf{c}$ via $2 \mathrm{c}$. 


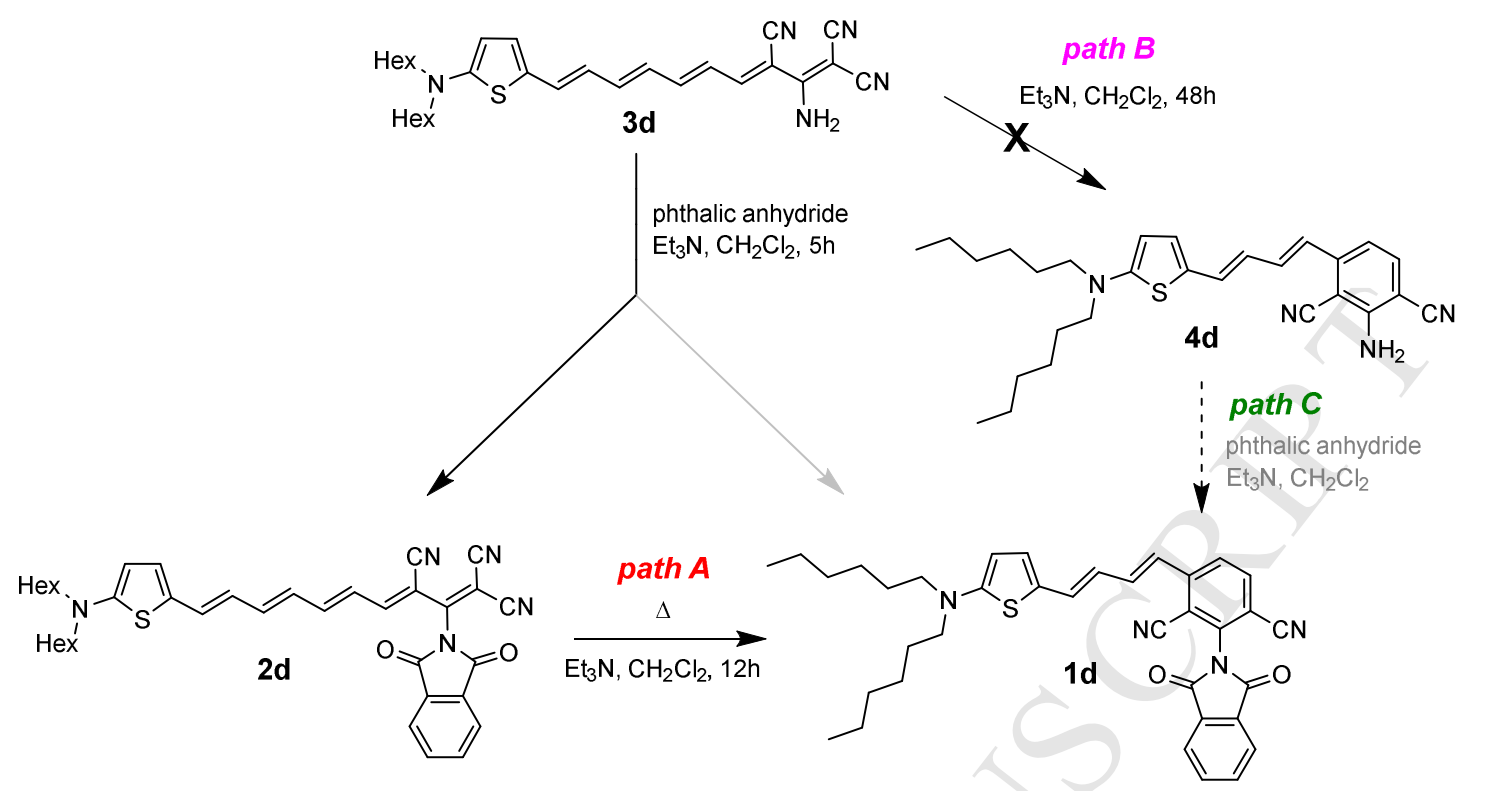

Figure 1. Rationale for the formation of $\mathbf{1 d}$ from $\mathbf{3 d}$.

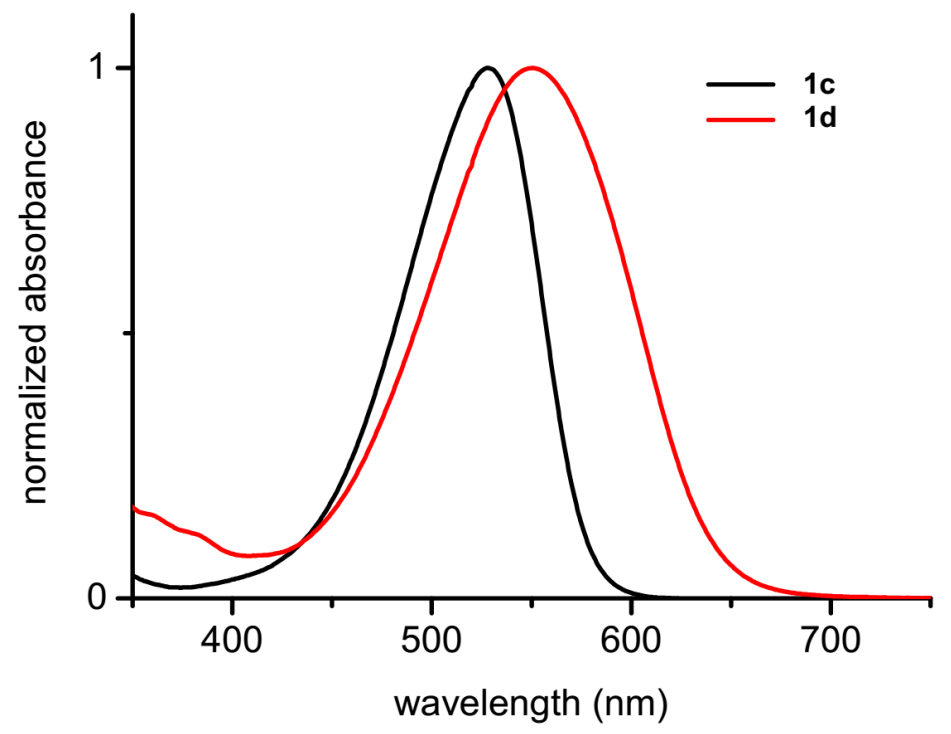

Figure 2. UV-vis absorption spectra of chromophores 1c (black) and 1d (red) in chloroform. 


\section{LEGENDS:}

Chart 1. General formula for the chemical structures of push-pull systems $\mathbf{1}$ and $\mathbf{2}$.

Chart 2: Push-pull polyenic chromophores 1 and 2, with for compound 1 the torsional angles $\theta_{1}$ $=\mathrm{S}-\mathrm{C}-\mathrm{C}-\mathrm{H}$ and $\theta_{2}=\mathrm{C}-\mathrm{C}-\mathrm{C}-\mathrm{C}_{\mathrm{CN}}$. In red, the conjugated segment considered for the calculation of the BLA (defined as the average of the differences in length of consecutive double and single carbon-carbon bonds along this segment). Cartesian frames used in the NLO calculations are also displayed. $N, N$-Dimethylaminothiophene was used in order to simplify the calculation.

Scheme 1. Preparation of the push-pull polyenic chromophores 1-3.

Scheme 2. Proposed mechanism for the formation of $1 \mathbf{c}$ from $3 \mathbf{c}$ via $2 \mathrm{c}$.

Figure 1. Rationale for the formation of $\mathbf{1 d}$ from $\mathbf{3 d}$.

Figure 2. UV-vis absorption spectra of chromophores 1c (black) and 1d (red) in chloroform. 
- Unprecedented intramolecular cyclization in strongly dipolar merocyanine dyes

- New magenta dyes

- Improved NLO-transparency-stability trade-off

- Novel class of dyes for NLO materials 